\title{
A PÁtria dOS OUTROS A “POESIA MENOR” DE MURILO MENDES
}

\author{
Ettore Finazzi-Agrò
}

Serei sempre o que esperou que lhe abrissem a porta ao pé de uma parede sem porta, E cantou a cantiga do Infinito numa capoeira, E ouviu a voz de Deus num poço tapado. Fernando Pessoa, "Tabacaria"

Pode ser um puro acaso que o texto abrindo a edição das obras completas de Murilo Mendes seja uma paródia da Canção do exílio'(MENDES, 1994, p. 87). E com certeza o é, visto o grande número de poemas, mais ou menos da mesma época, tomando como pré-texto ou como palimpsesto a célebre composição de Gonçalves Dias, mas tratase de um lance de dados, de um poema-piada - de uma jogada lírica, enfim, que não consegue abolir o hasard ligado ao fato de o autor ter sido, durante boa parte da sua existência e da sua atuação como escritor e intelectual, um "exilado".

A noção de exílio, como se sabe, é uma noção complexa e hiperconotada, um paradigma em que cabem multíplices e heterogêneas experiências, mas uma vida que se declina sob o signo do exílio, do estar "fora de lugar", do ser um outsider, acaba com certeza por produzir

1 De agora em diante este volume vai ser indicado pela sigla $P C P$. 
uma visão do mundo peculiar, na sua irredutibilidade a uma identidade marcada e a um ponto de vista garantido e unívoco. Compartilho neste sentido, modestamente, a preocupação de Edward Said com a exclusão programática de qualquer elemento pessoal ou biográfico na leitura das obras literárias em casos, como o de Murilo, em que a vivência e a convivência com culturas, com sociedades, mas também, ou sobretudo, com espaços e tempos impróprios - formalmente ou substancialmente "de outros" - acaba por produzir uma língua e uma linguagem literária peculiares (Cf. SAID, 2008, pp. 10-12).

É evidente que o "exílio" vivido pelo poeta do séc. XX seja bem diferente daquele cantado pelo autor do séc. XIX, embora se trate, em ambos os casos, de um afastamento voluntário, ligado, no caso de Gonçalves Dias, aos seus estudos junto à Universidade de Coimbra, e, no caso de Murilo, a uma escolha pessoal de "abandono" (voltarei sobre este termo) da pátria, rumo a uma imersão, quase sem retorno, na cultura européia. Mas aquilo que resta, nos dois casos, é a combinação de afastamento e de proximidade em relação a um espaço pátrio e paterno, relido do interior de uma situação de alheamento. O fato, em suma, de ser poeta brasileiro em terra estrangeira não pode ser considerado um elemento sem conseqüências, embora a estranheza em relação ao lugar onde se vive seja atravessada e como que corrompida ou atenuada pela consciência de viver num âmbito cultural que é a matriz e o ninho da cultura a que se pertence.

Esta situação intrincada acaba por criar uma condição de ubiqüidade da escrita poética que, no momento em que se dirige para o espaço próprio, para a terra de origem, não consegue se desvencilhar do lugar em que é produzida. Basta para isso considerar como a Canção do exílio traga, como citação prévia, alguns versos do célebre poema "Mignon" que Goethe dedicou à Itália - e em particular, ao que parece, à Sicília -, vista como lugar edênico onde "os limoeiros florescem"². A saudade da

2 Para facilitar o confronto entre o texto goethiano e os poemas de Gonçalves Dias e Murilo Mendes, pode ser útil transcrever por inteiro "Mignon" que aparece, como se sabe, no interior do Wilhelm Meister: "Kennst du das Land, wo die Zitronen blühn, / Im dunkeln Laub die Gold-Orangen glühn, / Ein sanfter Wind vom blauen Himmel weht, / Die Myrte still und hoch der Lorbeer steht? / Kennst du es wohl? / Dahin! Dahin / Möcht ich mit dir, o mein Geliebter, ziehn. // Kennst du das Haus? Auf Säulen ruht sein Dach, /Es glänzt der Saal, es schimmert das Gemach, / Und Marmorbilder stehn und sehn mich an: / Was hat man dir, du armes Kind, getan? / Kennst du es wohl? / Dahin! Dahin / Möcht ich mit dir, o mein Beschützer, ziehn. // Kennst du den Berg und seinen Wolkensteg? / Das Maultier sucht im Nebel seinen Weg, / In Höhlen wohnt der Drachen 
pátria é relida, nesse sentido, do interior de uma nostalgia poética alheia, da mitificação de um lugar longínquo e feliz atuada por um escritor alemão. Isto acaba por produzir aquilo que poderia ser ainda definido como "heterogênese dos fins", embaralhando as cartas do imaginário, visto que a exaltação da pátria longínqua por parte de Gonçalves Dias é declinada sob o signo de uma rememoração melancólica da Itália por parte do grande poeta alemão, acabando por confundir e deixar em aberto toda aquela rígida dicotomia entre o aqui e o lá sobre a qual se sustenta, aparentemente, o poema do brasileiro.

A esta condição, a mesmo tempo substancial e formal, de terceiredade, de não pertença nem a um lugar nem ao outro, não pode se subtrair o poeta moderno, ciente de habitar um limiar entre as culturas, entre tempos e espaços que são diferentes na sua identidade e idênticos na sua diversidade. Nesse sentido, a relação travada por Murilo com a Itália é marcada por uma irreparável heterotopia, por uma situação de reconhecimento na diferença e de espelhamento numa identidade radical da qual ele e a cultura da qual ele é portador e representante não pode prescindir. E mais uma vez, nessa transição do próprio ao impróprio e vice-versa, na fresta que se abre entre estranhamento e reconhecimento aparece a Sicília como espaço-tempo suspenso e terceiro, como fronteira ideal em que o pátrio e o estrangeiro se conjugam numa neutralidade sem escape.

Os poemas que compõem Siciliana se apresentam de fato, na minha opinião, como lugares de entrada e saída da cultura européia, relendo a grande e mestiça tradição da ilha italiana com os olhos de alguém que daquela tradição se percebe como descendente e antenado, como filho inquieto e progenitor atento. Cito, como exemplo, a "Meditação de Agrigento":

Quem nos domara a força vã, Quem nos sufocara o instinto

Para permanecermos

Em conformidade à linha do céu, A estas colunas perenes,

Ao oculto mar lá embaixo.

alte Brut; /Es stürzt der Fels und über ihn die Flut. / Kennst du ihn wohl? / Dahin! Dahin / Geht unser Weg! o Vater, laß uns ziehn!”. Como se sabe, Gonçalves Dias colocou em epígrafe à "Canção do exílio" o dístico inicial e o quinto, sexto e (parcialmente) o sétimo verso deste poema. 
Quem nos transformara em folha

Ou no súbito lagarto

Que se esgueira sob tuas pedras,

Templo F, sereno templo $F$,

Arquitetura de reserva e paz.

Transformar-se ou não, eis o problema.

Durar na zona limite da memória,

Nos limbos da vontade,

Ou submeter a pedra, cumprir o ofício rude,

Aprender do lavrador e do soldado.

Qual a forma do poeta? Qual seu rito?

Qual sua arquitetura?

Mudo, entre capitéis e cactos

Subsiste o oráculo.

A manhã doura a pedra e vagos nomes,

Agrigento me contempla, e vou-me. (PCP, pp. 567-68)

Como se vê, aqui estamos longe da Sicília ou, mais em geral, da Itália cantada por Goethe, longe daquele Land imaginário e romântico dominado pela natureza. Aqui, pelo contrário, estamos no cerne da cultura e da interrogação artística, no âmago de uma situação que é, ao mesmo tempo, de aproximação e afastamento: o poeta americano entende a maravilha do artefato antigo, da "arquitetura de reserva e paz" montada pelos gregos, mas nele vê também o questionamento do seu ofício artístico presente, colocando-se no limiar entre o factível e o feito, entre a pura possibilidade ("os limbos da vontade") e a prática poética ("o ofício rude").

Nesse sentido, Murilo reconhece a sua dívida para com aquela tradição milenar, sente, por assim dizer, o peso da pedra, mas, por outro lado, entende o mistério da pedra: o mistério insolúvel, oracular, de uma praxe que é também a sua - a do poeta moderno - forjando, às duras penas, a matéria, para extrair dela o imaterial da palavra poética. Artifex e artesão, ele se dá conta, então, que entre "a pedra e os vagos nomes" corre o enigma do seu ser um poeta déplacé, constantemente fora do seu lugar e todavia bem dentro daquele espaço que é, desde sempre, o seu. E a Sicília torna-se assim, não a utopia goethiana onde, idealmente, ir morar ("Dahin, dahin! / Möcht' ich...ziehn"), mas a dimensão atópica da travessia, da ida-e-volta - ou melhor, a concretização espacial daquilo que poderia ainda se chamar de in-between: um limiar abolindo as fronteiras e até a própria noção de espaço como dimensão medida, dividida sempre entre um dentro e um fora. 
Não por acaso, vários poemas de Siciliana contêm verbos de movimento, começando justamente por "Meditação de Agrigento" ("Agrigento me contempla, e vou-me) e passando pelo dístico abrindo e se repetindo no começo da estrofe final da "Canção de Termini Imerese”:

A Termini Imerese eu vim,

De Termini Imerese eu vou.

Transformei-me à minha imagem,

E o mesmo oráculo sou. (PCP, p. 568)

Em contraste, então, com a imagem pedregosa, de terra parada, imobilizada nos seus antigos hábitos pelo calor e pelo sol a pino, que prevalece na descrição da paisagem siciliana, aparece esta figura de poeta-viajante que vai e vem entre os tempos, se reconhecendo no estranhamento, no des-afastamento, na longínqua proximidade que o transforma em si mesmo, reivindicando o seu papel oracular, de portador de um "claro enigma".

Porque é isto que o poeta andarilho, o poeta exilado, o poeta morando - sem de-morar - num espaço estrangeiro atribui a si mesmo: esta capacidade de ver para além das aparências, devotando, todavia, ao modo de aparecer uma obstinada dedicação. E aqui surge, mais uma vez, o seu lado biográfico: porque Murilo, nos vários testemunhos sobre ele e na minha lembrança, sempre foi respeitoso da forma, eu diria até que ele foi sempre muito formalista na sua maneira de tratar com os outros. Mas esse respeito formal nunca lhe vedou ir além de qualquer convenção: modernista, surrealista, concretista, classicista sem nunca endossar por completo nenhum desses ismos, assim como o seu catolicismo nunca foi, para ele, uma verdadeira prisão ética ou uma bandeira ideológica3. Aquilo que sempre o caracterizou e que em Siciliana se mostra em toda a sua evidência, foi a sua devoção total - e, ela sim, quase religiosa - à arte em todas as suas manifestações ou epifanias: é esta a forma na qual e pela qual ele se achou desde sempre convocado e que lhe permitiu viver o exílio como oportunidade - oportunidade de reconstruir um "ser-emcomum", fora e longe da sua comunidade.

Deixando de lado, por falta de tempo e de competência específica, a sua atuação como crítico de arte e a sua convivência com pintores,

3 Leia-se, a respeito, o magistral ensaio de Raúl Antelo, “Concisão e Convergência”. In Letterature d'America, V, 23 (Estate, 1984), p. 26: "A convergência maior da heterotopia muriliana consiste, pois, na operação de fusão de tradições heterogêneas a partir das quais o poeta redefine o sistema literário pós-modernista”. 
escultores e historiadores italianos, acho todavia que esta nova comunidade da qual ele conseguiu participar e que ele, aliás, conseguiu construir fora e longe da sua Pátria tem reflexos relevantes também na sua prática poética ${ }^{4}$. Em primeiro lugar, no seu ser ela constelada pela alusão explícita a escritores, artistas e intelectuais: com efeito, um pouco à maneira de Manuel Bandeira ou de Drummond, também a poesia de Murilo - e talvez com mais freqüência e com mais convicção - parece querer se incluir numa comunidade artística, numa genealogia poética que, por sua vez, alimenta e influencia os seus versos. Posso me referir apenas aos italianos, mas é evidente, mais em geral, o desejo do poeta "exilado" de instituir, no "fora", um "dentro" potencial, constituído por personalidades artísticas que ele admira, por lugares que acabam por fazer parte e até por delimitar o seu discurso artístico.

De fato, os seus Grafitos e os seus Murilogramas, cheios de antropônimos e topônimos, não são mais de que tentativas de combater a dispersão do sujeito e da sua palavra em direção daquilo que ele chama de "Convergência":

\section{Lacerado pelas palavras-bacantes \\ Visíveis tácteis audíveis \\ Orfeu \\ Impede mesmo assim sua diáspora \\ Mantendo-lhes o nervo \& a ságoma. \\ Orfeu Orftu Orfele \\ Orfnós Orfuós Orfeles. (PCP, p. 625)5}

Aqui torna-se evidente a necessidade de evitar a diáspora ou a dispersão do $\mathrm{Eu}$, convocando todas as possíveis instâncias, todos os possíveis sujeitos, a fim de instituir, todavia, um cronótopo próprio e exclusivo, um sentido em comum - abeirando-se, talvez, daquela que Georges Bataille definia "a comunidade daqueles que não têm comunidade": ou seja, a comunhão daqueles que não conseguem se comunicar, a massa dos excluídos, daqueles, justamente, que viveram um afastamento progressivo do espaço pátrio e paterno e que querem mesmo assim, no ter abandonado o lugar de origem, cultivar no

4 Sobre esse aspecto e sobre as relações de Murilo com os artistas plásticos estrangeiros e, sobretudo, italianos -, continua sendo fundamental o livro organizado por L. Stegagno Picchio, Murilo Mendes. L'occhio del poeta. Roma: Gangemi, 2001.

5 O título deste poema é, na verdade, "Exergo" e constitui uma espécie de limiar dando acesso aos textos de Convergência (compostos entre 1963 e 1966). 
abandono a esperança de uma comunhão, de uma nova e diferente pátria, tentando se enraizar naquela "ausência de lugar" onde, segundo Simone Weil, se pode finalmente "captar, como todos os santos, aquilo que é o comprimento, a largura, a altura e a profundidade" (WEIL, 1985, p. 252).

Uma dimensão, repare-se, que por um lado fica inclusiva, alargandose até conter todos aqueles que compartilham a mesma angústia de viver e o mesmo desejo de exprimir, através da arte, a ambição absurda de vencer a morte e o silêncio, mas que, pelo outro, é exclusiva e, por isso mesmo, política, fundada, como é, sobre a escolha de fugir (a)o poder da língua, de se exilar no lugar onde a expressão encontra o seu oposto. É justamente esse lugar extremo, incluindo o outro no mesmo gesto com que o exclui, que ocupa, a meu ver, a produção poética em italiano de Murilo - publicada póstuma e, talvez, capaz, por esta razão trágica e ao mesmo tempo fatal, de nos dar conta daquele mistério que se esconde e se revela na relação entre o ser-eu e o ser-outro (ou o ser outro do eu, ou o ser eu do outro). Não por acaso, o poema abrindo Ipotesi coloca em primeiro plano, não mais o sujeito poético declinado em todas as suas variantes (“Orf-eu, Orf-tu, Orf-ele”...), mas o sujeito tornado anônimo e objetivo:

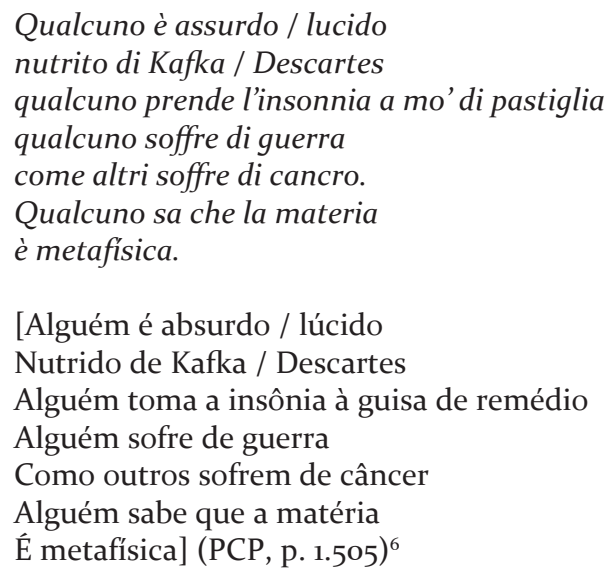

Neste ponto final da produção de Murilo, nos encontramos perante uma comunidade fundada não mais na comunhão entre sujeitos, mas na exposição do indivíduo ao seu ser-qualquer, abrindo para uma

6 A tradução em português, desta como das outras citações tiradas de Ipotesi, é minha. 
comunidade que vem (na bela imagem de Giorgio Agamben), ou seja, para uma "comunidade sem pressupostos e sem sujeitos", em que o "qualquer" seria "a figura de uma singularidade pura" que não participa de nenhuma propriedade, consistindo apenas no seu "confinar com”, no seu ser um limiar entre um dentro e um fora que permite fazer experiência do Outro sem sair de si mesmos. (AGAMBEN, 1990, pp. 45-46)

Nesse sentido, tudo indica, a partir da escolha lingüística, que com Ipotesi Murilo chega a se livrar de toda ambição de resolver o enigma da existência. Ou seja, se exprimindo numa língua que lhe é própria sendo estrangeira, o poeta abdica de qualquer veleidade de identificação (o ser brasileiro ou italiano assim como o ser surrealista ou realista), para se entregar a uma comunhão integral baseada numa singularidade qualquer que, por isso - como mostrou ainda Agamben -, joga um papel político, a partir da abdicação em relação ao uso pré-determinado, obrigatório da língua pátria e paterna, para chegar a uma indiferença que contem, em si mesma, um função eversiva em relação a uma Ordem imposta e préestabelecida:

Qualcuno odia le dittature / le patate fritte

qualcuno si vede circondato da insetti o da ipotesi.

[Alguém odeia as ditaduras / as batatas fritas

Alguém se vê rodeado por insetos ou hipóteses] (PCP, p. 1505)

Nem sujeito nem objeto, nem kafkiano nem cartesiano, e, ao mesmo tempo, tanto uma coisa quanto a outra, Murilo encontra finalmente, nesse espaço ocupado por uma identidade neutra, o centro geométrico da existência no seu despedir-se dela, a razão do ser-com num abandono da comunidade que é extremo abandono à comunidade.

Os poemas de Ipotesi são, com efeito, atravessados por um prenúncio de morte, por uma intenção de despedida que é todavia, em sentido cristão ou talvez messiânico, abertura para uma dimensão de volta: "Ritorno" é, justamente, o título do breve poema concluindo a seção denominada Epigrammi ed altro e abrindo para a seguinte intitulada Omaggi, na qual o poeta retoma a forma dos Epitáfios e dos

7 Que Ipotesi aluda a essa reversibilidade de todo evento extremo, é confirmado, aliás, por um poema como "La catastrofe" (PCP, pp. 1.509-10) que, de fato, assim se conclui: "La catastrofe infine / è quasi sempre reversibile" (“A catástrofe enfim / é quase sempre reversível"). Sobre esse sentido de "virada", de "reviravolta" que a palavra catástrofe encerra, ver ainda: NATOLI, 1999, pp. 196-200. 
Murilogramas ${ }^{7}$. Mais uma vez a comunidade da arte, a definição poética dos lugares, a evocação memorial e saudosa dos tempos e das pessoas: é este o limiar de que falei antes, é este o espaço intermédio e impossível onde qualcuno se e nos encontra e onde nós nos desencontramos na nossa identidade.

\section{Il suo cervello fu rivoluzionario \\ la sua fisiologia conservatrice. \\ Cercò sempre di abbinare \\ ragione e fantasia.}

Fece la guerriglia contro se stesso

capi l'irrealtà della realtà.

Crocefisse il Cristo

E liberò Barabba.

[O seu cérebro foi revolucionário

A sua fisiologia conservadora.

Procurou sempre conjugar

Razão e fantasia.

Fez a guerrilha contra si mesmo

Entendeu a irrealidade da realidade.

Crucificou Cristo

E libertou Barabas] (PCP, p. 1507)

O poeta que, pelo menos desde Siciliana, tentou teimosamente "colocar em conjunto coisas impossíveis" (na definição aristotélica da linguagem oracular, muito pertinente, aliás, para quem tinha se identificado, como vimos, com o próprio oráculo: "o mesmo oráculo sou") - o poeta, então, no seu "Epitáfio" conjugado no passado e aberto para o futuro, escrito, aliás, numa língua que não é a sua (ou é a sua apenas no estranhamento), reconhece enfim a sua hybris, a sua ousadia e o seu pecado, mas define todavia, pelo próprio fato de se exprimir num idioma estrangeiro, a sua função mediana e mediadora, a sua condição hipotética e, ao mesmo tempo, inabalável, cavada dentro de uma tradição que não é nem própria nem alheia ou que é própria no seu ser de outros.

No âmbito dessa "literatura menor" - para aproveitar o título de um importante ensaio de Gilles Deleuze e Félix Guattari sobre Kafka e sobre a sua escolha de escrever em alemão em terra tcheca - se coloca enfim Murilo Mendes: compondo versos em italiano ou em francês, sem nunca abdicar, porém, a sua brasilidade; compondo poemas em português, 
se abrigando sempre no interior da cultura européia. Porque, como afirmam os dois filósofos franceses, "o adjetivo menor não qualifica mais certas literaturas mas as condições revolucionárias de toda literatura no interior daquela outra literatura que toma o nome de grande (ou estabelecida)" (DELEUZE, GUATTARI, 1996, p. 33). E a Murilo, convicto admirador de Kafka ("me transformar em K letra já desaparecida") (PCP, p. 1.517$)^{8}$, revolucionário pelo menos no cérebro embora fisiologicamente conservador, balançando sempre no in-between, no interstício inexeqüível entre Europa e América, entre ordem e desordem, entre fé e desespero, se pode enfim aplicar a bela imagem que Deleuze e Guattari utilizaram para definir a urgência de expressão que inquietou o grande escritor tcheco e que volta a se manifestar no poeta brasileiro: "Escrever como um cão que faz o seu buraco, como um rato cavando a sua cova. E, para esse fim, encontrar o seu ponto de subdesenvolvimento, um dialeto próprio, um terceiro mundo, um deserto todo para si”. (DELEUZE, GUATTARI, p. 33)

É nessa dimensão terceira e exclusiva, balançando entre "insetos e hipóteses”, entre o que é e o que pode vir a ser; é, enfim, nesse deserto espaço arcaico e promessa de uma forma vindoura - que encontraremos sempre, no extravio e na perda, o poeta sem pátria e com muitas pátrias que foi e ainda é Murilo Mendes: no seu incessante "Ritorno", ou melhor, no seu obstinado habitar, com a sua poesia "menor", o limiar impossível que ele próprio estabeleceu, com coragem e com pena, entre todas as possíveis hipóteses.

\section{REFERÊNCIAS BIBLIOGRÁFICAS}

AGAMBEN, Giorgio. La comunità che viene. Torino: Einaudi, 1990.

ANTELO, Raúl. “Concisão e Convergência”. In Letterature d’America, V, 23 (Estate, 1984). DELEUZE, Gilles; GUATTARI, Félix. Kafka. Per una letteratura minore. Macerata: Quodlibet, 1996 (ed. or.: Kafka - Pour une littérature mineure. Paris: Minuit, 1975).

MENDES, Murilo. Poesia completa e prosa. Org. por L. Stegagno Picchio. Rio de Janeiro: Nova Aguilar, 1994.

NATOLI, Salvatore. Progresso e Catastrofe. Dinamiche della modernità. Milano: Christian Martinotti, 1999.

SAID, Edward W. Nel segno dell'esilio. Milano: Feltrinelli, 2008 (ed. or.: Reflexions on Exile. Cambridge MA: Harvard U.P., 20oo).

WEIL, Simone. Quaderni. Vol. II. Milano: Adelphi, 1985 (ed. or.: Cahiers, II. Paris: Plon, 1972).

8 "Trasformarmi in K lettera ormai scomparsa". 